\title{
ESTADO DO CONHECIMENTO DA PRODUÇÃO ACADÊMICA SOBRE A FORMAÇÃO DE PROFESSORES PARA O ENSINO DE ESTATÍSTICA
}

\author{
STATE OF KNOWLEDGE OF THE ACADEMIC PRODUCTION ON THE \\ TRAINING OF TEACHERS FOR THE TEACHING OF STATISTICS
}

\author{
Karla Priscila Schreiber ${ }^{1}$ \\ Mauren Porciúncula ${ }^{2}$
}

\begin{abstract}
Resumo: Esta pesquisa bibliográfica objetivou apresentar um Estado do Conhecimento das produções acadêmicas disponibilizadas no Banco de Teses da CAPES e na Biblioteca Digital Brasileira de Teses e Dissertações (BDTD), visando investigar a formação de professores para o ensino de Estatística. A análise de conteúdo das 19 publicações selecionadas foi realizada a partir de duas categorias prédefinidas: i) formação inicial do professor de Matemática; ii) formação continuada dos professores que ensinam Estatística. Na primeira categoria, as investigações enfatizaram o currículo e a proposição e avaliação de estratégias para o ensino de Estatística no curso de Licenciatura em Matemática. Para a formação continuada, os trabalhos contemplaram práticas colaborativas e formações por meio de cursos, oficinas e projetos. Tais pesquisas demonstraram movimentos dos professores em prol da formação para $o$ ensino de Estatística, seja por meio de práticas colaborativas ou pela participação em atividades relacionadas à prática pedagógica.
\end{abstract}

Palavras-chave: Educação Estatística; Pesquisas acadêmicas; Estado do Conhecimento.

\begin{abstract}
This bibliographic research aimed to present a State of Knowledge of the academic productions made available in the CAPES Digital Bank of Theses Summaries and the Brazilian Digital Library of Theses and Dissertations (BDTD), aiming to investigate the training of teachers for the teaching of Statistics. The content analysis of the 19 selected publications was carried out from two predefined categories: i) initial training of the mathematics teacher; ii) continuing education of teachers teaching Statistics. In the first category, the investigations emphasized the curriculum and the proposal and evaluation of pedagogical strategies for the teaching of Statistics in the course of Mathematics Degree. For ongoing training, the work included collaborative practices and other types of training, such as courses, workshops, and projects. Such research has demonstrated teachers' movements in favor of training for the teaching of Statistics, either through collaborative practices or participation in activities related to pedagogical practice.
\end{abstract}

Keywords: Statistical Education; Academic research; State of Knowledge.

\section{Introdução}

Esta pesquisa bibliográfica objetivou apresentar um Estado do Conhecimento das teses e dissertações disponibilizadas no Banco de Teses da Comissão de

\footnotetext{
${ }^{1}$ Mestre em Biometria e Estatística Aplicada pela Universidade Federal Rural de Pernambuco (UFRPE). Doutoranda no Programa de Pós-Graduação em Educação em Ciências pela Universidade Federal do Rio Grande (FURG), Rio Grande, RS, Brasil. E-mail: karla.pschreiber@ hotmail.com

${ }^{2}$ Doutora em Informática na Educação pela Universidade Federal do Rio Grande do Sul (UFRGS). Professora associada na Universidade Federal do Rio Grande (FURG) no Programa de Pós-Graduação em Educação em Ciências, Rio Grande, RS, Brasil. E-mail: mauren@ furg.br
} 


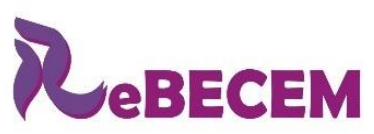

Revista Brasileira de Educação em

Ciências e Educação Matemática

ISSN 2594-9179

DOI: http://dx.doi.org/10.33238/ReBECEM.2019.v.3.n.2.22518

Aperfeiçoamento de Pessoal de Nível Superior - CAPES $^{3}$ e da Biblioteca Digital Brasileira de Teses e Dissertações - BDTD ${ }^{4}$, do Instituto Brasileiro de Informação em Ciência e Tecnologia - IBICT, visando sistematizar e discutir a produção acadêmica sobre a formação de professores para o ensino de Estatística, de modo a fomentar o debate e a reflexão. A escolha desta temática resulta do foco da pesquisa de doutorado da primeira autora, sob orientação da segunda autora, as quais investigam a formação de professores em Educação Estatística.

Por formação docente, compreende-se, assim como Passos et al., (2006, p. 195), como uma "formação contínua e de desenvolvimento profissional, pois pode ser entendida como um processo pessoal, permanente, contínuo e inconcluso que envolve múltiplas etapas e instâncias formativas". A formação contínua "é um fenômeno que ocorre ao longo de toda a vida e que acontece de modo integrado às práticas sociais e às cotidianas escolares de cada um, ganhando intensidade e relevância em algumas delas" (PASSOS et al., 2006, p. 195).

Educação Estatística, temática elegida para este artigo, surgiu na década de 1970, a partir de um movimento mundial que "reconheceu a importância do desenvolvimento do raciocínio probabilístico, a necessidade de romper com a cultura determinística nas aulas de Matemática, a dimensão política e ética do uso da Estatística” (CAZORLA; KATAOKA; SILVA, 2010, p. 19). No Brasil, os conceitos estatísticos foram incorporados, oficialmente, à disciplina de Matemática com a publicação dos Parâmetros Curriculares Nacionais - PCN, no Ensino Fundamental (BRASIL, 1997, 1998) e no Ensino Médio (2002; 2006), e, mais recentemente, com na Base Nacional Comum Curricular - BNCC (BRASIL, 2018).

Embora a Estatística e a Probabilidade estejam contempladas nas propostas curriculares da Matemática, Costa e Nacarato (2011) indicam, a partir de uma pesquisa com professores de escolas públicas e privadas e com professores formadores, que a formação inicial ou continuada não vem contribuindo para a construção do repertório de saberes disciplinares, pedagógicos e curriculares, necessários para o desafio de formar o pensamento estocástico de seus alunos. Lopes (2008, p. 70) também indica, considerando resultados de pesquisas relacionadas à Educação Estatística e à Educação Matemática, que a formação dos professores não incorpora o "trabalho sistemático

\footnotetext{
${ }^{3}$ Disponível em: http://catalogodeteses.capes.gov.br/catalogo-teses/\#!/

${ }^{4}$ Disponível em: http://bdtd.ibict.br/vufind/
} 


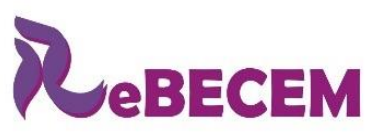

Revista Brasileira de Educação em

Ciências e Educação Matemática

ISSN 2594-9179

DOI: http://dx.doi.org/10.33238/ReBECEM.2019.v.3.n.2.22518

sobre estocástica ${ }^{5}$, dificultando a possibilidade desses profissionais desenvolverem um trabalho significativo com essa temática nas salas de aula da educação básica”.

Diante desse contexto, a fim de atender o objetivo proposto, a próxima seção apresentará os aspectos metodológicos e os procedimentais utilizados para conduzir este Estado do Conhecimento. Em seguida, serão sistematizadas e discutidas as teses e dissertações que fizeram parte deste corpus textual selecionado. Por fim, são indicadas algumas considerações acerca dos resultados discutidos nesse artigo.

\section{Aspectos metodológicos e procedimentais}

Esta pesquisa bibliográfica é caracterizada como qualitativa (BOGDAN; BIKLEN, 1994; GIL, 2010) e segue o delineamento de um Estado do Conhecimento, pois a sistematização e a discussão da produção acadêmica se restringiram às pesquisas disponibilizadas no Banco de Teses da CAPES e da BDTD/IBICT. O Estado do Conhecimento é caracterizado pela "identificação, registro, categorização que levem à reflexão e síntese sobre a produção científica de uma determinada área, em um determinado espaço de tempo, congregando periódicos, teses, dissertações e livros sobre uma temática específica” (MOROSINI; FERNANDES, 2014, p. 155).

Assim como o Estado da Arte, o Estado do Conhecimento configura-se como estudo bibliográfico invariante, no qual se realiza a sistematização da produção científica em determinada área do conhecimento. O Estado da Arte abrange uma área do conhecimento, considerando seus diferentes aspectos (ROMANOWSKI; ENS, 2006, p. 39); enquanto o Estado do Conhecimento apresenta uma amplitude menor, restringindose a uma fonte de pesquisa (FERREIRA, 2002; ROMANOWSKI; ENS, 2006).

Tendo isso em vista, neste Estado do Conhecimento foram consideradas as teses e dissertações que abordaram a formação de professores para o ensino de Estatística. Os descritores definidos para a busca foram: "formação de professores", "desenvolvimento profissional", "educação estatística", "ensino de estatística" e "tratamento da informação". Não houve restrição em relação ao período de publicação dos trabalhos.

A pesquisa foi realizada entre agosto e setembro de 2018, resultando em 50 trabalhos na BDTD/IBICT e 83 no Banco de Teses da CAPES, sendo selecionadas 19 publicações - nove teses e dez dissertações, conforme exposto no Quadro 1. Os demais foram excluídos do corpus textual, pois não abordaram a Educação Estatística e/ou

\footnotetext{
${ }^{5}$ Estocástica é o termo utilizado para referenciar a Probabilidade integrada à Estatística.
} 
DOI: http://dx.doi.org/10.33238/ReBECEM.2019.v.3.n.2.22518 discutiram práticas pedagógicas/formação com estudantes ou com professores dos Anos Iniciais do Ensino Fundamental ou da Educação Infantil. Além disso, um trabalho foi retirado da pesquisa, pois não foi possível acessar o resumo/trabalho final, impossibilitando o processo de análise. Ademais, três trabalhos foram recuperados nas duas bases de dados, sendo, neste caso, considerados uma única vez.

Quadro 1: Relação de teses e dissertações selecionadas para o corpus textual

\begin{tabular}{|c|c|c|c|c|}
\hline Fonte & $\begin{array}{c}\text { Tese ou } \\
\text { Dissertação }\end{array}$ & Instituição & Orientador (a) & $\begin{array}{c}\text { Título da tese/dissertação } \\
\text { (AUTOR, ano) }\end{array}$ \\
\hline \multirow{5}{*}{ BDTD/IBICT } & Tese & $\begin{array}{l}\text { Universidade } \\
\text { Estadual de } \\
\text { Londrina }\end{array}$ & $\begin{array}{l}\text { Prof. }^{\mathrm{a}} \text { Dr. }{ }^{\mathrm{a}} \\
\text { Márcia Cristina } \\
\text { de Costa } \\
\text { Trindade Cyrino }\end{array}$ & $\begin{array}{l}\text { Práticas de uma comunidade de } \\
\text { professores que ensinam } \\
\text { matemática e o desenvolvimento } \\
\text { profissional em Educação } \\
\text { Estatística (ESTEVAM, 2015). }\end{array}$ \\
\hline & Dissertação & $\begin{array}{c}\text { Pontifícia } \\
\text { Universidade } \\
\text { Católica de São } \\
\text { Paulo }\end{array}$ & $\begin{array}{l}\text { Prof. }{ }^{\text {a }} \text { Dr. }{ }^{\text {a }} \text { Célia } \\
\text { Maria Carolino } \\
\text { Pires }\end{array}$ & $\begin{array}{l}\text { O tratamento da informação: } \\
\text { currículos prescritos, formação de } \\
\text { professores e implementação na } \\
\text { sala de aula (SANTOS, 2005). }\end{array}$ \\
\hline & Tese & $\begin{array}{l}\text { Universidade } \\
\text { Estadual de } \\
\text { Campinas }\end{array}$ & $\begin{array}{l}\text { Prof. }^{\text {a }} \text { Dr. } \\
\text { Dione Lucchesi } \\
\text { de Carvalho }\end{array}$ & $\begin{array}{l}\text { Os saberes profissionais dos } \\
\text { professores = a problematização } \\
\text { das práticas pedagógicas em } \\
\text { estatística mediadas pelas práticas } \\
\text { colaborativas (COELHO, 2010). }\end{array}$ \\
\hline & Tese & $\begin{array}{l}\text { Universidade } \\
\text { Estadual de } \\
\text { Campinas }\end{array}$ & $\begin{array}{l}\text { Prof. }^{\text {a }} \text { Dr. } \\
\text { Dione Lucchesi } \\
\text { de Carvalho }\end{array}$ & $\begin{array}{c}\text { A formação estatística e } \\
\text { pedagógica do professor de } \\
\text { matemática em comunidades de } \\
\text { pratica (PAMPLONA, 2009). }\end{array}$ \\
\hline & Dissertação & $\begin{array}{l}\text { Universidade } \\
\text { Estadual de } \\
\text { Campinas }\end{array}$ & $\begin{array}{l}\text { Prof. }^{\text {a }} \text { Dr. } \\
\text { Dione Lucchesi } \\
\text { de Carvalho }\end{array}$ & $\begin{array}{l}\text { Professores e alunos construindo } \\
\text { saberes e significados em um } \\
\text { projeto de estatística para a } 6^{\mathrm{a}} \text { serie: } \\
\text { estudo de duas experiências em } \\
\text { escolas pública e particular } \\
\text { (MEGID, 2002). }\end{array}$ \\
\hline \multirow{3}{*}{$\begin{array}{l}\text { BDTD/IBICT } \\
\text { CAPES }\end{array}$} & Dissertação & $\begin{array}{l}\text { Universidade do } \\
\text { Noroeste do } \\
\text { Estado do Rio } \\
\text { Grande do Sul }\end{array}$ & $\begin{array}{l}\text { Prof. }{ }^{\text {a }} \text { Dr. }{ }^{\text {a }} \text { Cátia } \\
\text { Maria Nehring }\end{array}$ & $\begin{array}{c}\text { Entendimentos do ensino da } \\
\text { estatística em cursos de } \\
\text { licenciamento: aproximações e } \\
\text { distanciamentos na formação do } \\
\text { professor de matemática (FUCHS, } \\
\text { 2013). }\end{array}$ \\
\hline & Tese & $\begin{array}{c}\text { Pontifícia } \\
\text { Universidade } \\
\text { Católica de São } \\
\text { Paulo }\end{array}$ & $\begin{array}{l}\text { Prof. }^{\text {a }} \text { Dr. } \\
\text { Cileda de } \\
\text { Queiroz e Silva } \\
\text { Coutinho }\end{array}$ & $\begin{array}{l}\text { Um estudo sobre a abordagem dos } \\
\text { conteúdos estatísticos em cursos de } \\
\text { Licenciatura em Matemática: uma } \\
\text { proposta sob a ótica da ecologia do } \\
\text { didático (GOULART, 2015). }\end{array}$ \\
\hline & Tese & $\begin{array}{l}\text { Universidade } \\
\text { Estadual } \\
\text { Paulista "Júlio } \\
\text { de Mesquita } \\
\text { Filho" }\end{array}$ & $\begin{array}{l}\text { Prof. }^{\text {a }} \text { Dr. } \\
\text { Maria Lúcia } \\
\text { Lorenzetti } \\
\text { Wodewotzki }\end{array}$ & $\begin{array}{c}\text { A prática como componente } \\
\text { curricular via Projeto Integrado de } \\
\text { Prática Educativa (PIPE) no ensino } \\
\text { de estatística na Universidade: } \\
\text { implementação e implicações na } \\
\text { Formação Inicial do Professor de } \\
\text { Matemática (SILVA, 2016). }\end{array}$ \\
\hline CAPES & Tese & $\begin{array}{l}\text { Universidade } \\
\text { Estadual } \\
\text { Paulista "Júlio } \\
\text { de Mesquita } \\
\text { Filho" } \\
\end{array}$ & $\begin{array}{l}\text { Prof. }^{\text {a }} \text { Dr. } \\
\text { Maria Lúcia } \\
\text { Lorenzetti } \\
\text { Wodewotzki }\end{array}$ & $\begin{array}{c}\text { Os Saberes Docentes Do Professor } \\
\text { Universitário Do Curso } \\
\text { Introdutório de Estatística } \\
\text { Expressos no Discurso dos } \\
\text { Formadores (MALARA, 2008). }\end{array}$ \\
\hline
\end{tabular}




\section{R}

Revista Brasileira de Educação em

Ciências e Educação Matemática

ISSN 2594-9179

DOI: http://dx.doi.org/10.33238/ReBECEM.2019.v.3.n.2.22518

\begin{tabular}{|c|c|c|c|}
\hline Dissertação & $\begin{array}{c}\text { Universidade de } \\
\text { Brasília }\end{array}$ & $\begin{array}{l}\text { Prof. Dr. } \\
\text { Cristiano } \\
\text { Alberto Muniz. }\end{array}$ & $\begin{array}{l}\text { Educação estatística no ensino } \\
\text { fundamental: discussões sobre a } \\
\text { práxis de professoras que ensinam } \\
\text { matemática no interior de Goiás } \\
\text { (GONÇALVES, 2005). }\end{array}$ \\
\hline Dissertação & $\begin{array}{l}\text { Universidade } \\
\text { Franciscana }\end{array}$ & $\begin{array}{l}\text { Prof. }^{\text {a }} \text { Dr. } \\
\text { Helena Noronha } \\
\text { Cury }\end{array}$ & $\begin{array}{l}\text { Estatística: uma proposta de } \\
\text { formação continuada para } \\
\text { professores de matemática do } \\
\text { ensino fundamental e médio } \\
\text { (DESSBESEL, 2013). }\end{array}$ \\
\hline Dissertação & $\begin{array}{l}\text { Universidade } \\
\text { São Francisco }\end{array}$ & $\begin{array}{c}\text { Prof. }^{\text {a }} \text { Dr. }{ }^{a} \text { Adair } \\
\text { Mendes } \\
\text { Nacarato. }\end{array}$ & $\begin{array}{l}\text { A Educação Estatística na } \\
\text { Formação do professor de } \\
\text { Matemática (COSTA, 2007). }\end{array}$ \\
\hline Tese & $\begin{array}{l}\text { Universidade } \\
\text { Cruzeiro do Sul }\end{array}$ & $\begin{array}{l}\text { Prof. }{ }^{\text {a }} \text { Dr. }{ }^{\text {a }} \text { Celi } \\
\text { Aparecida } \\
\text { Espasandin } \\
\text { Lopes }\end{array}$ & $\begin{array}{c}\text { O Desenvolvimento Profissional de } \\
\text { Professores em Estatística: um } \\
\text { projeto Multi-dimensional de } \\
\text { Formação Colaborativa (SOUZA, } \\
\text { 2013). }\end{array}$ \\
\hline Dissertação & $\begin{array}{l}\text { Universidade } \\
\text { Anhanguera de } \\
\text { São Paulo }\end{array}$ & $\begin{array}{l}\text { Prof. Dr. Ruy } \\
\text { César } \\
\text { Pietropaolo }\end{array}$ & $\begin{array}{l}\text { Conhecimentos de professores de } \\
\text { Matemática sobre o processo de } \\
\text { ensino e de aprendizagem de } \\
\text { noções estatísticas - curva normal } \\
\text { (MACEDO, 2016). }\end{array}$ \\
\hline Dissertação & $\begin{array}{l}\text { Universidade } \\
\text { Anhanguera de } \\
\text { São Paulo }\end{array}$ & $\begin{array}{l}\text { Prof. Dr. Ruy } \\
\text { César } \\
\text { Pietropaolo }\end{array}$ & $\begin{array}{c}\text { Conhecimentos de professores para } \\
\text { o ensino da leitura e construção de } \\
\text { gráficos estatísticos na educação } \\
\text { básica (SERA, 2016). }\end{array}$ \\
\hline Tese & $\begin{array}{c}\text { Pontifícia } \\
\text { Universidade } \\
\text { Católica de São } \\
\text { Paulo } \\
\end{array}$ & $\begin{array}{c}\text { Prof. }^{\text {a }} \text { Dr. }^{\text {a }} \\
\text { Cileda de } \\
\text { Queiroz e Silva } \\
\text { Coutinho } \\
\end{array}$ & $\begin{array}{l}\text { O Teorema Central do Limite: um } \\
\text { estudo ecológico do saber e do } \\
\text { didático (RODRIGUES, 2009). }\end{array}$ \\
\hline Dissertação & $\begin{array}{c}\text { Pontifícia } \\
\text { Universidade } \\
\text { Católica de São } \\
\text { Paulo } \\
\end{array}$ & $\begin{array}{l}\text { Prof. }^{\text {a }} \text { Dr. }{ }^{a} \text { Célia } \\
\text { Maria Carolino } \\
\text { Pires }\end{array}$ & $\begin{array}{c}\text { Trajetórias Hipotéticas de } \\
\text { Aprendizagem em Estatística no } \\
\text { Ensino Médio (TONNETTI, 2010). }\end{array}$ \\
\hline Tese & $\begin{array}{l}\text { Universidade } \\
\text { Cruzeiro do Sul }\end{array}$ & $\begin{array}{l}\text { Prof. }{ }^{\text {a }} \text { Dr. }{ }^{\text {a }} \text { Celi } \\
\text { Aparecida } \\
\text { Espasandin } \\
\text { Lopes }\end{array}$ & $\begin{array}{c}\text { Reflexões e ações de professores } \\
\text { sobre modelagem Matemática na } \\
\text { Educação Estatística em um grupo } \\
\text { colaborativo (MENDONÇA, } \\
\text { 2015). }\end{array}$ \\
\hline Dissertação & $\begin{array}{l}\text { Universidade } \\
\text { Federal de } \\
\text { Uberlândia }\end{array}$ & $\begin{array}{c}\text { Prof. Dr. } \\
\text { Arlindo José de } \\
\text { Souza Junior }\end{array}$ & $\begin{array}{l}\text { Trabalho de Projetos no processo } \\
\text { de ensinar e aprender estatística na } \\
\text { universidade (CAMPOS, 2007). }\end{array}$ \\
\hline
\end{tabular}

Fonte: Acervo das autoras (2018)

Para a síntese e discussão dos trabalhos selecionados para o corpus textual desta pesquisa foram consideradas as etapas metodológicas da Análise de Conteúdo, a qual consiste em um conjunto de técnicas para a análise de comunicações (BARDIN, 2016). Para isso, inicialmente, foi realizada a leitura do título e do resumo das teses e dissertações recuperadas no Banco de Teses da CAPES e da BDTD/IBICT, a fim de conhecer e estabelecer familiaridade com os textos.

Neste primeiro momento, os trabalhos que não apresentaram relação com a formação de professores para o ensino de Estatística foram excluídos das etapas 


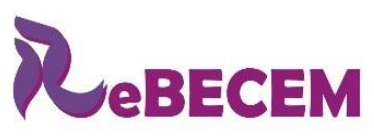

Revista Brasileira de Educação em

Ciências e Educação Matemática

ISSN 2594-9179

DOI: http://dx.doi.org/10.33238/ReBECEM.2019.v.3.n.2.22518

seguintes da análise. As pesquisas selecionadas receberam marcações coloridas - no resumo, no qual foram destacados o objetivo, a metodologia e os principais resultados, gerando as primeiras aproximações temáticas. Em alguns casos, quando o resumo não apresentava todos os elementos que estavam sendo analisados, também foram avaliadas as considerações finais/conclusões da pesquisa.

No processo de codificação e categorização, as teses e dissertações foram sistematizadas considerando a questão norteadora: "O que vem sendo discutido nas teses e dissertações brasileiras sobre a formação de professores para o ensino de Estatística?". Os trabalhos selecionados neste Estado do Conhecimento foram organizados em duas categorias pré-definidas: i) formação inicial do professor de Matemática; ii) formação continuada dos professores que ensinam Estatística. Em cada uma dessas categorias, subcategorias emergiram do corpus textual, as quais reagruparam a produção acadêmica em relação ao objetivo principal de cada pesquisa. Estes resultados são descritos e discutidos na seção seguinte.

\section{Resultados e discussões}

Nesta seção, organizada em duas partes, são apresentadas as categorias que foram consideradas para sistematizar as teses e dissertações que fizeram parte do corpus textual. Em cada uma delas o leitor encontrará um breve resumo do objetivo, da metodologia e dos principais resultados, apontados pelo autor da pesquisa. Além disso, são apresentadas algumas aproximações e discussões das temáticas abordadas nas teses e dissertações recuperadas no Banco de Teses da CAPES e da BDTD/IBICT, elaboradas pelas autoras deste artigo.

\subsection{Formação inicial do professor de Matemática}

Nesta categoria, os pesquisadores enfatizaram pesquisas relacionadas à formação inicial de professores de Matemática, a partir de seis trabalhos - três teses e três dissertações. Entre estas, duas temáticas foram investigadas: a) o currículo do curso de Licenciatura em Matemática; e b) proposição e avaliação de estratégias pedagógicas para o ensino de Estatística no curso de Licenciatura em Matemática.

O currículo do curso de Licenciatura em Matemática foi abordado por três pesquisadores (COSTA, 2007; FUCHS, 2013; GOULART, 2015). Entre estes, Costa (2007) investigou como professores da escola básica percebiam a inserção da Educação 
DOI: http://dx.doi.org/10.33238/ReBECEM.2019.v.3.n.2.22518

Estatística no currículo escolar e como professores formadores compreendiam a formação em Estocástica do futuro professor de Matemática. A partir das respostas obtidas por meio de um questionário, aplicado com professores da escola básica, indicou que a maioria dos docentes não recebeu uma formação inicial para os conteúdos que compõem o bloco "Tratamento da Informação", tornando o ensino baseado, principalmente, em livros didáticos e paradidáticos. Os professores formadores também reconheceram a existência de lacunas na formação inicial dos Licenciandos em Matemática, problemas conceituais e epistemológicos nos livros didáticos da Educação Básica, além da pouca flexibilidade do currículo do curso de Licenciatura em Matemática, o que indicou a necessidade de repensar o curso, considerando a formação do pensamento estatístico dos futuros professores para que estes possam se sentir seguros quando estiverem atuando na Educação Básica.

Fuchs (2013) analisou como a Educação Estatística estava sendo discutida na formação inicial de professores de Matemática, em universidades públicas e privadas do Rio Grande do Sul. Para isso, em uma análise documental, avaliou os projetos pedagógicos e as matrizes curriculares dos cursos, as ementas e os planos de ensino das disciplinas de Estatística e Probabilidade, seguida de uma pesquisa de campo, onde aplicou um questionário com os coordenadores dos cursos e professores que ministravam estas disciplinas. Concluiu, a partir dos currículos e dos entendimentos dos coordenadores, que os cursos enfatizavam a formação dos licenciandos para as demandas inerentes ao contexto escolar da Educação Básica, em relação à formação para a cidadania, com o desenvolvimento do pensamento analítico, crítico e reflexivo do futuro professor de Matemática. Contudo, indicou, considerando as respostas dos professores formadores, que havia lacunas na formação inicial do professor de Matemática, pois o ensino da Estatística e da Probabilidade ainda estava sendo baseado em cálculos, fórmulas e procedimentos algébricos, e, muitas vezes, não considerava a ideia de variabilidade e/ou aleatoriedade, ou então, discussões relativas ao aspecto pedagógico destes conteúdos.

Goulart (2015) avaliou o currículo do curso de Licenciatura em Matemática e a relação deste com o ensino de Estatística na Educação Básica. A partir da Teoria Antropológica do Didático - TAD e da perspectiva Ecológica, indicou dois grandes ecossistemas: o ensino de Matemática na Educação Básica e o curso de Licenciatura em Matemática. Considerou os documentos: PCN de terceiro e quarto ciclos do Ensino Fundamental (Matemática), os PCN do Ensino Médio (Ciências da Natureza, 
DOI: http://dx.doi.org/10.33238/ReBECEM.2019.v.3.n.2.22518

Matemática e suas Tecnologias), os PCN+ (Ciências da Natureza, Matemática e suas Tecnologias), as Orientações Curriculares para o Ensino Médio (Ciências da Natureza, Matemática e suas Tecnologias), as Diretrizes Curriculares Nacionais para os Cursos de Matemática, Bacharelado e Licenciatura (DCN-BL) e as Diretrizes Curriculares Nacionais para a Formação de Professores da Educação Básica, em Nível Superior, Curso de Licenciatura, de graduação plena (DCN-FP). Além disso, analisou os exames de larga escala: Sistema de Avaliação da Educação Básica - SAEB, Prova Brasil, Exame Nacional do Ensino Médio - ENEM e Exame Nacional de Desempenho dos Estudantes - ENADE; e duas coleções de livros didáticos aprovadas pelo Plano Nacional do Livro Didático - PNLD e destinadas à Educação Básica. Para a Educação Básica, os resultados indicaram a existência de discussões relativas à elaboração e à interpretação de gráficos e tabelas de frequência, mas o ensino das medidas de tendência central e de dispersão se restringia aos cálculos, assim como na Licenciatura em Matemática, na qual a ênfase também estava na manipulação de algoritmos. Além disso, na formação de professores, a Probabilidade e a Estatística faziam parte, em geral, de uma disciplina com carga horária de 60 horas, sendo a Estatística vista como um ramo da Matemática. Por fim, não encontrou relações que pudessem ser formadas entre a sala de aula da Educação Básica e o curso de Licenciatura em Matemática para que fosse possível potencializar a formação do professor em relação ao Letramento Estatístico, pois, embora os objetos estatísticos existissem em ambos os ecossistemas, estes estavam isolados e não apresentavam nenhuma inter-relação.

Também discutindo a formação do futuro professor de Matemática, três trabalhos destacaram a proposição e a avaliação de estratégias pedagógicas no ensino e na aprendizagem da Estatística (CAMPOS, 2007; RODRIGUES, 2009; SILVA, 2016). Entre estes, Campos (2007) analisou as contribuições do Projeto Pedagógico Trabalho de Projetos no desenvolvimento profissional de estudantes, da Faculdade de Matemática, da Universidade Federal de Uberlândia, em uma disciplina de Estatística e Probabilidade. O pesquisador indicou, a partir de observações, documentos relativos ao projeto, questionário e entrevistas, que os estudantes, ao participarem desta proposta, passaram a desenvolver saberes relacionados ao ensino com pesquisa, ao trabalho colaborativo, à utilização de recursos computacionais, à metodologia de projetos e à investigação dentro de métodos estatísticos, contribuindo, assim, para a formação profissional. 


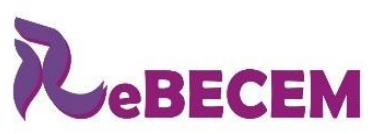

\section{Revista Brasileira de Educação em \\ Ciências e Educação Matemática \\ ISSN 2594-9179}

DOI: http://dx.doi.org/10.33238/ReBECEM.2019.v.3.n.2.22518

Com destaque ao Teorema Central do Limite, Rodrigues (2009) investigou a construção das ideias e de conceitos matemáticos e/ou estatísticos por licenciandos do curso de Matemática. Embasado na Teoria da Transposição Didática, em uma abordagem ecológica sob o ponto de vista do saber e do didático, analisou livros-texto do Ensino Superior à luz da Teoria Antropológica do Didático, desenvolveu atividades relacionadas ao contexto de atuação dos professores de Matemática e analisou como foram construídas as ideias e conceitos do Teorema Central do Limite pelos discentes. Como resultados, indicou que os livros-texto apresentaram a definição do teorema (sem expor as demonstrações) e as aplicações, com problemas associados ao contexto matemático e/ou do cotidiano. Com as atividades, a estrutura ecológica do saber e do didático foi contemplada, pois os saberes indispensáveis para a definição do Teorema Central do Limite foram delimitados. Por fim, reiterou a importância do ensino e da aprendizagem da Estatística na formação do professor de Matemática.

Já Silva (2016) analisou o Projeto Integrado de Prática Educativa - PIPE 6 , na disciplina de Estatística e Probabilidade, em um curso de formação de professores de Matemática, a partir da inserção da Prática como Componente Curricular - PCC. Para a pesquisa, considerou os documentos e os seus registros no diário de campo, entrevistas com os professores, questionários com os alunos e um ambiente virtual, durante cinco semestres letivos. Como resultados, apontou que existiam falhas nos registros de experiências do PIPE, dúvidas conceituais em relação a essa componente e divergências na visão dos docentes quanto à concepção da PCC via PIPE. Contudo, os licenciandos entendiam o projeto como um espaço diferenciado para o desenvolvimento profissional, pois, em relação à Estatística, possibilitava o trabalho em conjunto entre teoria e prática, principalmente pela transdisciplinaridade desta área do conhecimento.

Nos trabalhos apresentados nesta categoria, os pesquisadores indicaram lacunas na formação do professor de Matemática (COSTA, 2007; FUCHS, 2013), assinalando, inclusive, a falta de relação entre os conceitos estatísticos discutidos na Educação Básica e a forma em que são abordados no curso de Licenciatura em Matemática (GOULART, 2015). Tal resultado é coerente ao já apontado por Lopes (2013, p. 903), a qual expôs que "não apenas os alunos da licenciatura em matemática se sentem

\footnotetext{
${ }^{6}$ Projeto Integrado de Prática Educativa - PIPE refere-se a um componente curricular criado pela Universidade Federal de Uberlândia - UFU, o qual foi inserido no Currículo dos Cursos de Licenciatura "como resposta às exigências de reformulação das Licenciaturas, constantes das Diretrizes Curriculares Nacionais para a Formação de Professores da Educação Básica, em Nível Superior, Curso de Licenciatura, de Graduação Plena (Resolução CNE/CP n. 01/2002), com relação à instituição da Prática como Componente Curricular" (SILVA, 2016, p. 123).
} 


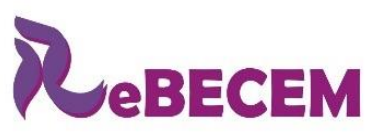

Revista Brasileira de Educação em

Ciências e Educação Matemática

ISSN 2594-9179

DOI: http://dx.doi.org/10.33238/ReBECEM.2019.v.3.n.2.22518

despreparados para abordar a estatística nas aulas de matemática da educação básica, mas a ausência de material didático que subsidie o trabalho docente é ampla”.

Cabe destacar que a Estatística está nos documentos educacionais brasileiros, na disciplina de Matemática, onde se espera que o estudante possa realizar processos de coleta, organização, comunicação e interpretação de dados, a partir de tabelas, gráficos e representações (BRASIL, 1997; 2006). A BNCC destaca que "todos os cidadãos precisam desenvolver habilidades para coletar, organizar, representar, interpretar e analisar dados em uma variedade de contextos, de maneira a fazer julgamentos bem fundamentados e tomar as decisões adequadas” (BRASIL, 2018, p. 274).

Logo, os futuros professores "precisam obter uma formação estatística que lhes permita pensar estatisticamente e aprender como promover o desenvolvimento do pensamento estatístico de seus futuros alunos" (LOPES, 2013, p. 912). Tal formação, em um curso de Licenciatura em Matemática, "precisa, não apenas, ter o quê, o porquê, o quem e o quando, mas, essencialmente, o como" (LOPES, 2013, p. 905). Com isso, "a educação estatística dos professores deve modelar uma pedagogia eficaz, enfatizando o pensamento estatístico e a compreensão conceitual, contando com a aprendizagem ativa e a exploração de dados reais, e fazendo uso efetivo da tecnologia e da avaliação" (FRANKLIN et al., 2015, p. 2, tradução nossa).

O como ensinar também foi contemplado nas teses e dissertações que fizeram parte desta categoria. Este foi discutido a partir de estratégias pedagógicas como o trabalho com projetos (CAMPOS, 2007), contexto de uma situação-problema (RODRIGUES, 2009) e a Prática como Componente Curricular (SILVA, 2016), apontando contribuições destas propostas para a formação do professor de Matemática.

\subsection{Formação continuada dos professores que ensinam Estatística}

Nesta categoria, os pesquisadores enfatizaram a formação continuada dos professores que ensinam Estatística na Educação Básica ou no Ensino Superior, a partir de 13 trabalhos - seis teses e sete dissertações. Entre estas, duas temáticas foram discutidas, considerando a formação docente a partir de: a) práticas colaborativas; b) cursos, oficinas e projetos.

Os grupos colaborativos, segundo Fiorentini (2004, p. 52-53), são constituídos por "pessoas voluntárias, no sentido de que participam do grupo espontaneamente, por vontade própria, sem serem coagidas ou cooptadas por alguém a participar”. Ao 


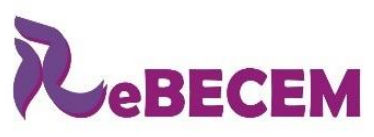

Revista Brasileira de Educação em

Ciências e Educação Matemática

ISSN 2594-9179

DOI: http://dx.doi.org/10.33238/ReBECEM.2019.v.3.n.2.22518

participarem destes grupos, professores, assim como licenciandos em processo de formação inicial, passam a analisar e discutir "problemas e desafios trazidos pelos professores, episódios de aula narrados e documentados pelos professores, e negociam conjuntamente significados e outras possibilidades de intervenção em suas práticas escolares, sobretudo tarefas e atividades exploratório-investigativas" (FIORENTINI, 2010, p. 582).

Entre os trabalhos que discutiram a formação e as práticas pedagógicas em grupos colaborativos, pode-se destacar a tese de Coelho (2010). Nesta, investigou como professores de Matemática da escola básica problematizavam suas concepções em relação à Educação Estatística nas práticas de ensinar e aprender Estatística, a partir da participação no Grupo Colaborativo em Educação Matemática - GCOEM, analisando também, os saberes que emergiram com a prática profissional. No grupo, os professores estudaram textos sobre Educação Estatística, planejaram aulas de Estatística, escreveram histórias sobre as aulas e um livro. Como resultados da pesquisa, apontou que as interações dialógicas entre os professores possibilitaram a sistematização e a mobilização de saberes profissionais, assim como o sentimento de poder e identificação profissional. Além disso, ressaltou a importância do currículo da Educação Básica incorporar práticas que promovam a Literacia Estatística e não se restrinjam ao ensino do cálculo matemático e da representação simplificada de gráficos.

A partir de questionários e da videogravação dos 11 encontros colaborativos, Souza (2013) analisou as contribuições do projeto de Formação Profissional Cíclica e Contínua de Professores em Estatística - FPCCPE$^{7}$ para o desenvolvimento e a mobilização de saberes no processo de ensino e de aprendizagem da Estatística de 16 professores de Matemática dos Anos Finais do Ensino Fundamental, em um processo de pesquisa-ação colaborativa. Neste projeto, buscou compreender como os professores poderiam, considerando comunidades profissionais, aprender a ensinar Estatística. $\mathrm{O}$ pesquisador apontou que os professores que trabalharam colaborativamente superaram a insegurança no ensino de Estatística, inseriram atividades investigativas e exploratórias em seus planejamentos, além de melhorarem o conhecimento conceitual e de conteúdo, utilizando recursos tecnológicos e adotando novas práticas em sala de aula.

\footnotetext{
${ }^{7} \mathrm{O}$ "projeto FPCCPE tem como base o princípio de que o desenvolvimento de professores deve ser gerido como um tempo de reflexão e de inovação, em vez de tempo para atualização", compreendendo cinco fases: orientação, exploração, implementação, análise e conclusão (SOUZA, 2013, p. 91).
} 


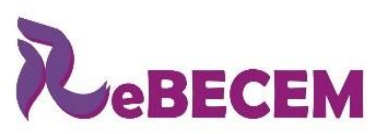

Revista Brasileira de Educação em
Ciências e Educação Matemática

DOI: http://dx.doi.org/10.33238/ReBECEM.2019.v.3.n.2.22518

Também considerando a formação de grupos colaborativos, Mendonça (2015) analisou as ações que eram favoráveis ao entendimento de professores da Educação Básica em relação à Modelagem Matemática para a abordagem da Educação Estatística, a partir das discussões relativas a este tema no Grupo de Investigação e Formação em Educação Matemática - GIFEM ${ }^{8}$. A pesquisadora apontou que, apesar de todas as ações vivenciadas no grupo colaborativo serem relevantes à reflexão, os professores demonstraram maior interesse por discussões relativas ao planejamento e à proposição de atividades que pudessem ser aplicadas na prática docente, sendo que estas propostas favoreceram a inserção de atividades de Modelagem Matemática em sala de aula. Entretanto, havia uma dependência pela intervenção pedagógica para que os procedimentos inerentes à Modelagem Matemática ocorressem.

De modo semelhante aos grupos colaborativos, as Comunidades de Prática (em inglês, community of practice, ou, simplesmente, CoP) são formadas, voluntariamente, entre sujeitos que buscam alcançar um objetivo comum (FIORENTINI, 2004). O termo foi cunhado e definido por Jean Lave e Etienne Wenger, em 1987, no Institute for Research on Learning, Palo Alto, Califórnia, sendo a representação de "grupos de pessoas que compartilham uma preocupação, um conjunto de problemas ou uma paixão por um tópico, e que aprofundam seu conhecimento e especialização nessa área pela interação numa base continuada" (LAVE; WENGER, 1991, p. 33, tradução nossa).

Nas Comunidades de Prática busca-se "o compartilhamento de experiências e histórias, o ajuste de diferentes interpretações de ações, dos significados que, não sendo idênticos entre os participantes, se inter-relacionam e acabam por se conjugar e ganhar coerência relativamente à prática que os une" (ESTEVAM, 2015, p. 49). Cabe ressaltar, segundo Fiorentini (2004), que a CoP não se caracteriza, necessariamente, como um grupo colaborativo. Ou seja:

A diferença básica resiste no fato de que todos os integrantes de um grupo
colaborativo assumem um mínimo de protagonismo no grupo, não se
reduzindo a meros auxiliares ou fornecedores de dados e materiais, mas como
sujeitos que não apenas aprendem, mas também produzem conhecimentos e
ensinam os outros (FIORENTINI, 2004, p. 61).

Neste contexto, considerando professores formadores e licenciandos do curso de Matemática como membros de uma mesma comunidade de prática, Pamplona (2009)

\footnotetext{
8 “O grupo foi formado no início de 2012 com adesão voluntária de professores da Educação Básica a um convite da segunda autora [Prof. ${ }^{a}$ Dr. ${ }^{a}$ Celi Aparecida Espasandin Lopes]. Sua dinâmica de discussão compreende a escolha de um tema para reflexão e ação no início de cada semestre em encontros quinzenais. A partir das discussões ali geradas, são elaboradas atividades aplicadas nas turmas em que os professores trabalham e, posteriormente, elas são socializadas no grupo" (MENDONÇA, 2015, p. 159).
} 


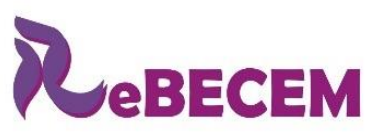

DOI: http://dx.doi.org/10.33238/ReBECEM.2019.v.3.n.2.22518

discutiu a aprendizagem-ensino da Estatística na formação do professor de Matemática, ressaltando as práticas pedagógicas nela envolvidas. Para isso, analisou as narrativas de professores experientes que atuavam no ensino de Estatística nos cursos de Licenciatura em Matemática, em universidades paulistas, com um instrumento da História Oral, a "Narrativa Bibliográfica". Como resultados, indicou que nas práticas que os professores formadores citaram, desenvolveram ou valorizaram, dada a formação estatística e pedagógica, havia um compartilhamento, com os licenciandos, dos problemas, das escolhas, dos trajetos, das perspectivas e dos prazeres da docência, em especial, no ensino de Estatística, além do questionamento das práticas de formação matemática/estatística e pedagógica, entre outras.

A partir da participação na Comunidade de Prática Refletir, Discutir e Agir sobre Matemática - CoP-ReDAMat e com a Análise de Tarefas Estatísticas - ATE (as quais envolviam ideias relacionadas às medidas de tendência central) e Análise de Vídeos de uma Aula de Estatística - AVAE (excertos de aulas videogravadas, tanto dos próprios professores que realizam as análises, quanto de terceiros), Estevam (2015) investigou o desenvolvimento profissional em Educação Estatística de um grupo de professores que ensinavam Matemática. Com a transcrição de audiogravações dos encontros do grupo, a produção escrita dos professores e os registros do pesquisador/formador, o autor concluiu que a $\mathrm{CoP}$ possibilitou o desenvolvimento coletivo dos professores em relação à Educação Estatística, sendo, para isso, necessária a articulação entre as atividades desenvolvidas no grupo, relacionadas às medidas de tendência central, e às práticas dos professores em sala de aula.

As pesquisas relacionadas às práticas colaborativas apontaram contribuições no desenvolvimento coletivo dos professores (ESTEVAM, 2015), com a inserção de novas práticas pedagógicas, a sistematização e a mobilização de saberes profissionais (COELHO, 2010), o compartilhamento de experiências entre docentes e licenciandos (PAMPLONA, 2009), além da superação da insegurança no ensino de Estatística (SOUZA, 2013). Ademais, os professores indicaram maior interesse em discussões associadas ao planejamento e à proposição de atividades que promovam o Letramento Estatístico em sala de aula (MENDONÇA, 2015).

Além das práticas colaborativas, a formação dos professores a partir de cursos, oficinas e projetos também foi discutida nas teses e dissertações recuperadas no Banco de Teses da CAPES e da BDTD/IBICT. Entre estas, Megid (2002) investigou a construção de saberes docentes e discentes em um projeto de Estatística, com turmas de 


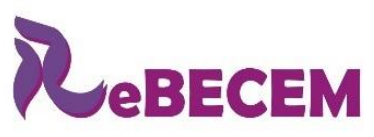

Revista Brasileira de Educação em

Ciências e Educação Matemática

ISSN 2594-9179

DOI: http://dx.doi.org/10.33238/ReBECEM.2019.v.3.n.2.22518

$6^{\text {a }}$ série (atual $7^{\circ}$ ano) de escolas públicas e privadas, a partir da análise do diário de campo, gravações em áudio e vídeo, entrevistas com alunos e com as professoras, além das produções escritas dos estudantes. Os dados foram analisados considerando duas categorias: o processo de produção e elaboração dos conhecimentos pelos alunos; e o processo de produção de conhecimentos pedagógicos e profissionais pela professora. Os resultados apontaram contribuições do projeto, entre estas: a mobilização de conhecimentos matemáticos - como o cálculo de porcentagem, cálculo com graus, gráficos e tabelas -, a interação entre alunos e destes com os professores, possibilitando o desenvolvimento do raciocínio, da flexibilidade do pensamento matemático e da linguagem matemática.

Gonçalves (2005), através de uma pesquisa-ação, analisou as construções e os processos presentes na práxis de professoras que ensinavam Matemática no Ensino Fundamental, em relação ao ensino de noções estocásticas. Para isso, a partir da vivência do cotidiano de uma professora de $4^{\mathrm{a}}$ série em uma escola pública e da constituição de um curso de extensão para professores que ensinavam Matemática no Ensino Fundamental, o pesquisador indicou três categorias: organização do trabalho pedagógico no contexto da Educação Estatística; desenvolvimento profissional das professoras em Educação Estatística; e obstáculos didáticos e epistemológicos no ensino de noções estocásticas. Apontou que o trabalho contribuiu para a formação continuada das professoras, pois estas tiveram um contato com noções estocásticas, construindo estas noções com atividades que envolviam jogos e experimentos.

Com ênfase nos conteúdos de Combinatória, Probabilidade e Estatística na Educação Básica, Santos (2005) avaliou o processo de incorporação destes conteúdos por um grupo de professores que participavam de um curso de formação continuada, com base em entrevistas e na observação de atividades desenvolvidas em sala de aula. Nas entrevistas, os docentes indicaram que não acreditavam na inserção destes conteúdos na Educação Básica, apresentando certa resistência por não dominarem ou por considerarem esses conceitos complexos. Os professores também expuseram que não conheciam o que os PCN indicavam para o ensino de Combinatória, Probabilidade e Estatística e que não haviam estudado estes conteúdos na graduação. Sobre o curso, o pesquisador indicou que este pode não ter contribuído para que os professores inserissem os conteúdos relacionados à Combinatória, Probabilidade e Estatística em sua prática docente, pois não houve discussões mais consistentes em relação ao ensino 


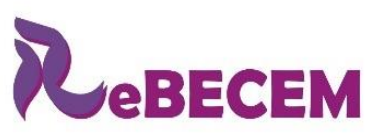

Revista Brasileira de Educação em

Ciências e Educação Matemática

ISSN 2594-9179

DOI: http://dx.doi.org/10.33238/ReBECEM.2019.v.3.n.2.22518

desses conteúdos em sala de aula, o que pode ter ocorrido devido ao pouco tempo destinado ao curso.

Já Malara (2008) analisou os saberes que professores formadores acreditavam ser necessários para a prática pedagógica de docentes que ministravam um curso introdutório de Estatística. A partir de entrevistas semiestruturadas com quatro formadores, de contato via correio eletrônico e de consulta ao material produzido pelos entrevistados, a pesquisadora indicou saberes, sendo estes: decorrentes das experiências com os estudantes; das concepções sobre a função do professor universitário; das compreensões sobre a aprendizagem; sobre como ensinar que definem paradigmas; do conteúdo específico; relacionados com a mobilização para o conhecimento; das estratégias de ensino e da tecnologia; relativos aos fatores que interferem na prática docente; pautados na postura pessoal do professor e educador; e relativos às dificuldades de aprendizagem do aluno.

Tonnetti (2010) apresentou uma pesquisa relacionada às estratégias pedagógicas no ensino de Estatística, considerando o projeto denominado "Construção de Trajetórias Hipotéticas de Aprendizagem e implementação de inovações curriculares em Matemática no Ensino Médio". Nesta pesquisa, investigou a compatibilização das perspectivas construtivistas de aprendizagem, considerando a planificação do ensino em Estatística. Também analisou o planejamento e o desenvolvimento de atividades relacionadas à Estatística, por dois professores de Matemática que atuavam no Ensino Médio. Para isso, a partir do Ciclo de Ensino de Matemática ${ }^{9}$, o pesquisador construiu uma primeira versão de uma proposta que se fundamentava em Trajetórias Hipotéticas de Aprendizagem - THA $^{10}$, a qual foi aplicada pelos professores em sala de aula. Esta foi apresentada aos professores para que pudessem qualificá-la e, com isso, se chegasse a uma segunda versão da THA. Contudo, os professores não colaboraram para que isso acontecesse, pois consideravam a proposta adequada, dentro do que acreditavam ser produtivo. Tal resultado indicou a relevância da postura docente para a inserção de práticas pedagógicas no ensino de Estatística na Educação Básica.

\footnotetext{
${ }^{9}$ Desenvolvido por Martin A. Simon, refere-se a um "modelo de inter-relações cíclicas, dos aspectos do conhecimento do professor, pensamento, tomada de atitudes" (TONNETTI, 2010, p. 22).

10 A THA considera três componentes: "o objetivo do professor com direções definidas para a aprendizagem de seus alunos, as atividades de ensino e o processamento hipotético de aprendizagem (uma suposição de como o pensamento e o entendimento dos alunos será colocado em ação no contexto de aprendizagem das atividades)" (TONNETTI, 2010, p. 23-24).
} 


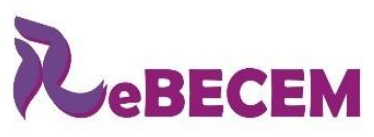

Revista Brasileira de Educação em

Ciências e Educação Matemática

ISSN 2594-9179

DOI: http://dx.doi.org/10.33238/ReBECEM.2019.v.3.n.2.22518

Abordando conteúdos de Estatística, Dessbesel (2013) analisou o ensino ministrado por professores de Matemática da Educação Básica e avaliou a realização de oficinas de formação continuada para professores de Matemática, a partir de um questionário, entrevistas e a realização de oficinas de formação continuada. Como resultados, indicou que no Ensino Fundamental os professores enfatizaram a organização de dados em uma tabela e a construção de gráficos de linhas e barras. No Ensino Médio, a ênfase estava na representação gráfica de dados e medidas de tendência central (média aritmética, mediana e moda). Os professores também enfatizaram a utilização do computador como recurso pedagógico e se mostraram dispostos a participarem de cursos de formação continuada desde que estes contribuíssem para a prática pedagógica em sala de aula.

Considerando o ensino de noções relacionadas à leitura da curva normal para alunos do Ensino Médio, Macedo (2016) investigou a ampliação na base de conhecimentos de um grupo de 15 professores de Matemática da Educação Básica, a partir de uma formação continuada, na qual os docentes realizaram reflexões compartilhadas e vivências sobre o currículo de Estatística e Probabilidade. Na primeira etapa, os professores responderam um questionário, no qual foram identificados os conhecimentos e as práticas docentes relativas às noções necessárias para a análise de uma curva normal. Em um segundo momento, os professores participaram de um processo formativo, no qual discutiram situações de aprendizagem sobre os significados de média, mediana e desvio padrão e a realização da leitura de uma curva normal. Como isso, indicou que estas reflexões possibilitaram que os docentes considerassem a introdução desses conceitos em sala de aula, especialmente, a análise da curva normal em contextos significativos para os discentes, ampliando a base de conhecimentos dos professores no ensino da Estatística e de Probabilidade.

Sera (2016) também investigou a ampliação da base de conhecimentos de um grupo de 15 professores de Matemática, neste caso, para a leitura e para a construção de gráficos estatísticos por estudantes dos Anos Finais do Ensino Fundamental e do Ensino Médio, considerando um curso de formação continuada. A partir de um questionário, o pesquisador identificou os conhecimentos e as práticas dos professores associadas ao ensino e à aprendizagem destes conteúdos. Em seguida, os professores participaram de um processo formativo, onde discutiram situações de aprendizagem relativas ao Letramento Estatístico, especialmente a leitura e a construção de gráficos. Como resultados, apontou que a prática reflexiva favoreceu a ampliação da base de 


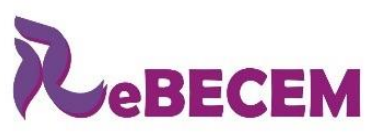

Revista Brasileira de Educação em

Ciências e Educação Matemática

ISSN 2594-9179

DOI: http://dx.doi.org/10.33238/ReBECEM.2019.v.3.n.2.22518

conhecimentos dos docentes e das próprias estratégias para o ensino da leitura de gráficos estatísticos.

Diante deste contexto, pode-se destacar a formação dos professores a partir de cursos, oficinas e projetos, os quais possibilitaram o desenvolvimento da base de conhecimentos dos professores para o ensino dos conceitos estatísticos (MEGID, 2002; MACEDO, 2016; SERA, 2016), de práticas e estratégias pedagógicas (GONÇALVES, 2005; TONNETTI, 2010), na utilização de recursos tecnológicos (DESSBESEL, 2013) e na mobilização de saberes docentes (MALARA, 2008). Contudo, Santos (2005) também ressaltou as dificuldades relativas à inserção da Estatística em sala de aula, o que pode ter ocorrido devido à existência de lacunas na formação inicial do professor de Matemática e o desconhecimento dos documentos oficiais que regulamentam a Educação Básica, além do curto período destinado aos cursos de formação continuada.

Esta dificuldade em desenvolver práticas pedagógicas em Estatística, apontada por Santos (2005), é coerente ao que Batanero (2001, p. 6, tradução nossa) já ressaltava, ou seja, embora a Estatística esteja inserida no currículo da Educação Básica, "na prática, ainda há poucos professores que incluem este tema e, em outros casos, são tratados de forma muito breve ou excessivamente formalizada". Com isso, apesar das recomendações dos PCN, pode-se considerar que a abordagem dos conceitos estatísticos ainda é pequena se comparada a outras áreas da Matemática como Álgebra, Geometria e Aritmética (BORBA et al., 2011).

Nesta categoria, as teses e dissertações apresentaram discussões relativas à formação do professor para o ensino de Estatística a partir de práticas colaborativas (PAMPLONA, 2009; COELHO, 2010; SOUZA, 2013; MENDONÇA, 2015; ESTEVAM, 2015) e de cursos, oficinas e projetos (MEGID, 2002; GONÇALVES, 2005; SANTOS, 2005; MALARA, 2008; TONNETTI, 2010; DESSBESEL, 2013; MACEDO, 2016; SERA, 2016). Estas pesquisas indicaram contribuições para o desenvolvimento profissional docente na promoção da Estatística, ampliando a base de conhecimento dos professores em relação aos conceitos, estratégias pedagógicas e recursos tecnológicos. Além disso, se discutiu os desafios associados à inserção destes conteúdos na Educação Básica, o interesse docente por propostas que abordem a prática em sala de aula e os saberes docentes e discentes mobilizados no ensino e na aprendizagem destes conteúdos.

As estratégias pedagógicas, direta e indiretamente, também estiveram contempladas nas teses e dissertações recuperadas no Banco de Teses da CAPES e da 
BDTD/IBICT. Em especial, Tonnetti (2010) demonstrou a relevância da postura docente diante das propostas de ensino, ou seja, o quanto o desenvolvimento de uma atividade pode ser modificado a partir da atuação docente em sala de aula, a qual está pautada nas concepções sobre como se deve ensinar. Logo, "a atuação do professor como mediador das situações de aprendizagem, sua postura diante de uma situação desafiadora e seu olhar reflexivo são elementos importantes para que ocorra uma evolução na educação" (TONNETTI, 2010, p. 102), o que transpassa um planejamento que, mesmo semelhante, poderá trazer diferentes contribuições à aprendizagem a contar pela forma em que é realizado em sala de aula e pela forma em que é compreendido pelos discentes.

\section{Considerações finais}

Este artigo apresentou um Estado do Conhecimento das publicações acadêmicas relacionadas à formação de professores para o ensino de Estatística, considerando as teses e dissertações disponibilizadas no Banco de Teses da CAPES e da BDTD/IBICT. Com a análise de conteúdo do corpus textual selecionado, foram indicados seis trabalhos que discutiram a formação inicial, no curso de Licenciatura em Matemática, e 13 que investigaram a formação continuada de professores que ensinavam Estatística na Educação Básica ou no Ensino Superior.

$\mathrm{Na}$ formação inicial, as pesquisas abordaram o currículo do curso de Licenciatura em Matemática e a proposição e avaliação de estratégias pedagógicas para o ensino de Estatística. Os pesquisadores indicaram lacunas na formação do professor para o ensino dos conceitos estatísticos, além de um distanciamento entre o ensino da Educação Básica e da Licenciatura em Matemática. Nas estratégias pedagógicas podemse destacar as contribuições da realização de projetos, de atividades relacionadas à prática do professor de Matemática e da integração entre a prática e a teoria.

$\mathrm{Na}$ formação continuada, em contextos colaborativos, as pesquisas apontaram a sistematização e a mobilização de saberes docentes, a superação da insegurança no ensino de Estatística e o interesse em discutir a proposição de atividades pedagógicas. Nas comunidades de prática, pode-se destacar o desenvolvimento coletivo e o compartilhamento de experiências entre professores e licenciandos de Matemática.

Os resultados relativos à formação em cursos, oficinas e projetos indicaram a ampliação da base de conhecimentos dos conteúdos e das estratégias pedagógicas para o 


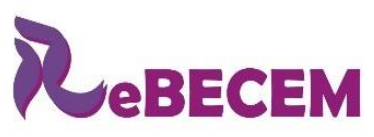

Revista Brasileira de Educação em

Ciências e Educação Matemática

DOI: http://dx.doi.org/10.33238/ReBECEM.2019.v.3.n.2.22518

ensino de Estatística, além da disposição dos professores em participar de espaços de formação que contribuam para a prática pedagógica. Ademais, também foram expostas fragilidades na formação e na prática docente, assim como a relevância da postura do professor no planejamento e no desenvolvimento das atividades em sala de aula.

Por fim, espera-se que este Estado do Conhecimento auxilie na proposição de outras pesquisas sobre a formação, inicial e continuada, dos professores que ensinam Estatística na Educação Básica e no Ensino Superior, trazendo novos conhecimentos e discussões. Considera-se que a produção acadêmica é um campo inesgotável para pesquisas, fato que favorece o preenchimento das possíveis e involuntárias lacunas desta investigação e a concretização de outras, uma vez que se entende este tipo de pesquisa como uma importante fonte de consulta científica.

Agradecimentos: O presente trabalho foi realizado com apoio da Coordenação de Aperfeiçoamento de Pessoal de Nível Superior - Brasil (CAPES) - Código de Financiamento 001.

\section{Referências}

BARDIN, L. Análise de conteúdo. Tradução de Luís Antero Reto e Augusto Pinheiro. $3^{\circ}$ reimp. da 1. ed. São Paulo: Edições 70, 2016.

BATANERO, C. Didáctica de la Estadística. 1. ed. Granada: GEEUG, Departamento de Didáctica de la Matemática, Universidad de Granada, 2001.

BOGDAN, R. C.; BIKLEN, S. K. Investigação qualitativa em educação. Tradução de Maria João Alvarez, Sara Bahia dos Santos e Telmo Mourinho Baptista. 1. ed. Porto: Porto Editora, 1994.

BORBA, R. E. S. MONTEIRO, C. E.; GUIMARÃES, G. L.; COUTINHO, C.; KATAOKA, V. Y. Educação Estatística no Ensino Básico: currículo, pesquisa e prática em sala de aula. Em Teia | Revista de Educação Matemática e Tecnológica Iberoamericana, Recife, v. 2, n. 2, p. 1-18, nov. 2011.

BRASIL. Ministério da Educação. Secretaria de Educação Fundamental. Parâmetros Curriculares Nacionais: Matemática. Primeiro e segundo ciclo do Ensino Fundamental. Brasília: MEC/SEF, 1997.

BRASIL. Ministério da Educação. Secretaria de Educação Fundamental. Parâmetros Curriculares Nacionais: Matemática. Terceiro e quarto ciclo do Ensino Fundamental. Brasília: MEC/SEF, 1998.

BRASIL. Ministério da Educação. Secretaria de Educação Média e Tecnológica. Parâmetros Curriculares Nacionais, Ensino Médio +: Ciências da natureza. Matemática e suas tecnologias. Brasília: MEC/SEMTEC, 2002. 
DOI: http://dx.doi.org/10.33238/ReBECEM.2019.v.3.n.2.22518

BRASIL. Ministério da Educação. Secretaria de Educação Básica. Orientações curriculares para o Ensino Médio - Ciências da natureza, Matemática e suas tecnologias. Brasília: MEC/SEB, 2006.

BRASIL. Ministério da Educação. Secretaria de Educação Básica. Base Nacional Comum Curricular. Brasília: MEC/SEB, 2018.

CAMPOS, S. G. V. B. Trabalho de projetos no processo de ensinar e aprender estatística na universidade. 2007. Dissertação (Mestrado em Ciências Humanas) - Universidade Federal de Uberlândia, Uberlândia, 2007.

CAZORLA, I. M.; KATAOKA, V. Y.; SILVA, C. B. Trajetória e Perspectivas da Educação Estatística no Brasil: um olhar a partir do GT12. In: LOPES, C. E.; COUTINHO, C. Q. S.; ALMOULOUD, S. A. (org.). Estudos e Reflexões em Educação Estatística. 1. ed. Campinas, SP: Mercado das Letras, 2010. p. 19-44.

COELHO, M. A. Os saberes profissionais dos professores: a problematização das práticas pedagógicas em estatística mediadas pelas práticas colaborativas. 2010. Tese (Doutorado em Educação) - Faculdade de Educação, Universidade Estadual de Campinas, Campinas, 2010.

COSTA, A. A Educação Estatística na formação do professor de Matemática. 2007. Dissertação (Mestrado em Educação) - Universidade São Francisco, Itatiba, 2007.

COSTA, A.; NACARATO, A. M. A Estocástica na Formação do Professor de Matemática: percepções de professores e de formadores. Boletim de Educação Matemática, Rio Claro, v. 24, n. 39, p. 367-386, ago. 2011.

DESSBESEL, R. S. Estatística: uma proposta de formação continuada para professores de Matemática do Ensino Fundamental e Médio. 2013. Dissertação (Mestrado em Ensino de Matemática) - Centro Universitário Franciscano, Santa Maria, 2013.

FERREIRA, N. S. A. As Pesquisas Denominadas “Estado Da Arte”. Educação \& Sociedade, Campinas, ano XXIII, n. 79, p. 257-272, ago. 2002.

FIORENTINI, D. Pesquisar práticas colaborativas ou pesquisar colaborativamente? In: BORBA, M. C.; ARAÚJO, J. L. (org.). Pesquisa qualitativa em Educação Matemática. 1. ed. Belo Horizonte: Autêntica, 2004. p. 47-76.

FIORENTINI, D. Desenvolvimento profissional e comunidades investigativas. In: DALBEN, A. et al. (org.). Convergências e tensões no campo da formação e do trabalho docente: Educação ambiental - Educação em ciências - Educação em espaços não escolares - Educação matemática. 1. ed. Belo Horizonte: Autêntica, 2010. p. 570-590.

FRANKLIN, C. A. et al. The statistical education of teachers. Alexandria, VA: American Statistical Association, 2015.

FUCHS, M. J. Entendimentos do ensino da estatística em cursos de licenciamento: aproximações e distanciamentos na formação do professor de matemática. 2013. Dissertação (Mestrado em Educação nas Ciências - área de Matemática) - Universidade Regional do Noroeste do Estado do Rio Grande do Sul, Ijuí, 2013.

GIL, A. C. Como elaborar projetos de pesquisa. 4. ed. São Paulo: Atlas, 2010. 
DOI: http://dx.doi.org/10.33238/ReBECEM.2019.v.3.n.2.22518

GONÇALVES, H. J. L. A Educação Estatística no ensino fundamental: discussões sobre a práxis de professoras que ensinam matemática no interior de Goiás. 2005. Dissertação (Mestrado em Educação) - Faculdade de Educação, Universidade de Brasília, Brasília, 2005.

GOULART, A. Um estudo sobre a abordagem dos conteúdos estatísticos em cursos de Licenciatura em Matemática: uma proposta sob a ótica da ecologia do didático. 2015. Tese (Doutorado em Educação) - Pontifícia Universidade Católica de São Paulo, São Paulo, 2015.

ESTEVAM, E. J. G. Práticas de uma Comunidade de Professores que ensinam Matemática e o Desenvolvimento Profissional em Educação Estatística. 2015. Tese (Doutorado em Ensino de Ciências e Educação Matemática) - Centro de Ciências Exatas, Universidade Estadual de Londrina, Londrina, 2015.

LAVE, J.; WENGER, E. Situated learning: legitimate peripheral participation. $1^{a}$ edição. Cambridge: Cambridge University Press, 1991.

LOPES, C. E. O ensino da Estatística e da Probabilidade na Educação Básica e a formação dos professores. Cad. Cedes, Campinas, v. 28, n. 74, p. 57-73, jan./abr. 2008.

LOPES, C. E. Educação estatística no curso de licenciatura em matemática. Boletim de Educação Matemática, Rio Claro, v. 27, n. 47, p. 901-915, dez. 2013.

MACEDO, R. C. Conhecimentos de professores de Matemática sobre o processo de ensino e de aprendizagem de noções estatísticas - curva normal. 2016. Dissertação (Mestrado em Educação Matemática) - Universidade Anhanguera de São Paulo, São Paulo, 2016.

MALARA, M. B. S. Os saberes docentes do professor universitário do curso introdutório de Estatística expressos no discurso dos formadores. 2008. Tese (Doutorado em Educação Matemática) - Instituto de Geociências e Ciências Exatas, Universidade Estadual Paulista, Rio Claro, 2008.

MEGID, M. A. B. A. Professores e alunos construindo saberes e significados em um projeto de estatística para a $6^{\mathbf{a}}$ serie: estudo de duas experiências em escolas pública e particular. 2002. Dissertação (Mestrado em Educação) - Faculdade de Educação, Universidade Estadual de Campinas, Campinas, 2002.

MENDONÇA, L. O. Reflexões e ações de professores sobre modelagem matemática na Educação Estatística em um grupo colaborativo. 2015. Tese (Doutorado em Ensino de Ciências e Matemática) - Universidade Cruzeiro do Sul, São Paulo, 2015.

MOROSINI; M. C.; FERNANDES, C. M. B. Estado do Conhecimento: conceitos, finalidades e interlocuções. Educação Por escrito, Porto Alegre, v. 5, n. 2, p. 154-164, jul./dez. 2014.

PAMPLONA, A. S. A formação estatística e pedagógica do professor de matemática em comunidades de prática. 2009. Tese (Doutorado em Educação) - Faculdade de Educação, Universidade Estadual de Campinas, Campinas, 2009.

PASSOS, C. L. B. et al. Desenvolvimento profissional do professor que ensina Matemática: uma meta-análise dos estudos brasileiros. Quadrante, Lisboa, v. XV, n. 1 e 2, p. 193-219, 2006.

RODRIGUES, C. K. O teorema central do limite: um estudo ecológico do saber e do didático. 2009. Tese (Doutorado em Educação) - Pontifícia Universidade Católica de São Paulo, São Paulo, 2009. 
DOI: http://dx.doi.org/10.33238/ReBECEM.2019.v.3.n.2.22518

ROMANOWSKI, J. P.; ENS, R. T. As pesquisas denominadas do tipo "estado da arte" em educação. Diálogo Educacional, Curitiba, v. 6, n. 19, p. 37-50, set./dez. 2006.

SANTOS, C. R. O tratamento da informação: currículos prescritos, formação de professores e implementação na sala de aula. 2005. Dissertação (Mestrado em Educação) - Pontifícia Universidade Católica de São Paulo, São Paulo, 2005.

SERA, E. K. Conhecimentos de professores para o ensino da leitura e construção de gráficos estatísticos na Educação Básica. 2016. Dissertação (Mestrado em Educação Matemática) - Universidade Anhanguera de São Paulo, 2016.

SILVA, M. A prática como componente curricular via Projeto Integrado de Prática Educativa (PIPE) no ensino de estatística na Universidade: implementação e implicações na Formação Inicial do Professor de Matemática. 2016. Tese (Doutorado Educação Matemática) Instituto de Geociências e Ciências Exatas, Universidade Estadual Paulista, Rio Claro, 2016.

SOUZA, L. O. O desenvolvimento profissional de professores em estatística: um projeto multi-dimensional de formação colaborativa. 2013. Tese (Doutorado em Ensino de Ciências e Matemática) - Universidade Cruzeiro do Sul, São Paulo, 2013.

TONNETTI, A. C. Trajetórias hipotéticas de aprendizagem em estatística no Ensino Médio. 2010. Dissertação (Mestrado em Educação) - Pontifícia Universidade Católica de São Paulo, São Paulo, 2010.

Recebido em: 30 de maio de 2019.

Aceito em: 07 de agosto de 2019. 